\title{
Front Matter: Volume 11413
}

, "Front Matter: Volume 11413," Proc. SPIE 11413, Artificial Intelligence and Machine Learning for Multi-Domain Operations Applications II, 1141301 (2 June 2020); doi: 10.1117/12.2572617

SPIE. Event: SPIE Defense + Commercial Sensing, 2020, Online Only 


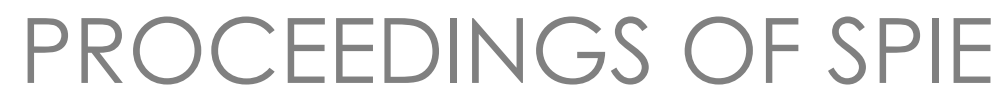

\section{Artificial Intelligence and Machine Learning for Multi-Domain Operations Applications II}

\section{Tien Pham}

Latasha Solomon

Katie Rainey

Editors

27 April - 8 May 2020

Online Only, United States

Sponsored and Published by

SPIE 
The papers in this volume were part of the technical conference cited on the cover and title page. Papers were selected and subject to review by the editors and conference program committee. Some conference presentations may not be available for publication. Additional papers and presentation recordings may be available online in the SPIE Digital Library at SPIEDigitalLibrary.org.

The papers reflect the work and thoughts of the authors and are published herein as submitted. The publisher is not responsible for the validity of the information or for any outcomes resulting from reliance thereon.

Please use the following format to cite material from these proceedings:

Author(s), "Title of Paper," in Artificial Intelligence and Machine Learning for Multi-Domain Operations Applications II, edited by Tien Pham, Latasha Solomon, Katie Rainey, Proceedings of SPIE Vol. 11413 (SPIE, Bellingham, WA, 2020) Seven-digit Article CID Number.

ISSN: 0277-786X

ISSN: 1996-756X (electronic)

ISBN: 9781510636033

ISBN: 9781510636040 (electronic)

Published by

SPIE

P.O. Box 10, Bellingham, Washington 98227-0010 USA

Telephone +1 3606763290 (Pacific Time) · Fax +1 3606471445

SPIE.org

Copyright (c) 2020, Society of Photo-Optical Instrumentation Engineers.

Copying of material in this book for internal or personal use, or for the internal or personal use of specific clients, beyond the fair use provisions granted by the U.S. Copyright Law is authorized by SPIE subject to payment of copying fees. The Transactional Reporting Service base fee for this volume is $\$ 21.00$ per article (or portion thereof), which should be paid directly to the Copyright Clearance Center (CCC), 222 Rosewood Drive, Danvers, MA 01923. Payment may also be made electronically through CCC Online at copyright.com. Other copying for republication, resale, advertising or promotion, or any form of systematic or multiple reproduction of any material in this book is prohibited except with permission in writing from the publisher. The CCC fee code is $0277-$ $786 \times / 20 / \$ 21.00$.

Printed in the United States of America by Curran Associates, Inc., under license from SPIE.

Publication of record for individual papers is online in the SPIE Digital Library.

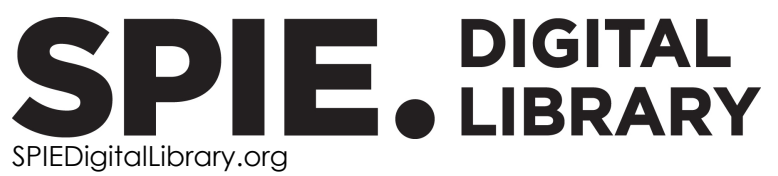

Paper Numbering: Proceedings of SPIE follow an e-First publication model. A unique citation identifier (CID) number is assigned to each article at the time of publication. Utilization of CIDs allows articles to be fully citable as soon as they are published online, and connects the same identifier to all online and print versions of the publication. SPIE uses a seven-digit CID article numbering system structured as follows:

- The first five digits correspond to the SPIE volume number.

- The last two digits indicate publication order within the volume using a Base 36 numbering system employing both numerals and letters. These two-number sets start with $00,01,02,03,04$, 05, 06, 07, 08, 09, OA, OB ... 0Z, followed by 10-1Z, 20-2Z, etc. The CID Number appears on each page of the manuscript. 


\section{Contents}

\section{MULTI-DOMAIN OPERATIONS}

1141304 The multi-domain operations effect loop: from future concepts to research challenges (Invited Paper) [11413-1]

1141305 Growing an artificial intelligence capability: challenges and opportunities [11413-2]

$1141306 \quad$ Minimizing data requirements for soldier-interactive Al/ML applications through opportunistic sensing [11413-3]

1141308 Test and evaluation needs of multi-domain autonomous systems [11413-5]

$1141309 \quad$ Network dynamics based multidomain sensor data processing and fusion for multidomain operations [11413-6]

$114130 \mathrm{~A} \quad$ Policy-based ensembles for multi domain operations [11413-7]

LEARNING AND REASONING WITH SMALL DATA SAMPLES, DIRTY DATA, HIGH CLUTTER, AND DECEPTION

$11413 \mathrm{OB} \quad$ Special datasets for training learning algorithms [11413-18]

11413 OC Achieving a trusted, reliable, Al-ready infrastructure for military medicine and civilian care [11413-19]

11413 OD Reasoning with small data samples for organised crime [11413-21]

11413 OE Repairing highly corrupted speech and images with U-net autoencoders [1 1413-22]

11413 OF Few-shot learning for defence and security [1 1413-23]

\section{AL-ENABLED SITUATION AWARENESS AND CONTEXT AWARE DECISION MAKING}

11413 OG Using Al/ML to predict perpetrators for terrorist incidents [1 1413-24] 
$11413 \mathrm{OH} \quad$ Al-enabled wargaming in the military decision making process [11413-25]

11413 ol A deep learning based methodology for video anomaly detection in crowded scenes [11413-26]

$114130 \mathrm{~J} \quad$ Improving situational awareness with collective artificial intelligence over knowledge graphs [11413-27]

NOVEL AI/ML FRAMEWORK AND ARCHITECTURES

11413 OK Evaluation framework for input layer preprocessing in a radial basis function neural network [11413-28]

$11413 \mathrm{OL} \quad$ An optimal end-to-end training strategy for multi-expert-based neural architecture [11413-29]

$11413 \mathrm{ON} \quad$ Beyond traditional architecture for MDO applications: the Erlang VM and its potential [11413-31]

1141300 A joint cross-modal super-resolution approach for vehicle detection in aerial imagery [11413-32]

\section{ADVERSARIAL MACHINE LEARNING AND SECURITY}

11413 OP Countermeasure against backdoor attacks using epistemic classifiers [1 1413-33]

$114130 Q \quad$ Efficacy of defending deep neural networks against adversarial attacks with randomization [11413-34]

11413 OR Cyber resilience using autonomous agents and reinforcement learning [11413-35]

11413 OS Adversarial attacks and countermeasures against ML models in army multi-domain operations [11413-37]

\section{HUMAN AGENT TEAMING}

11413 OT Network analyses for bioinspired configurations of human and multiple entity teams [11413-38]

11413 OU Measuring complacency in humans interacting with autonomous agents in a multi-agent system [1 1413-39]

$114130 \mathrm{~V} \quad$ Human swarm interaction using plays, audibles, and a virtual spokesperson [11413-40] 
11413 OW Connecting soldiers with relay robots in challenging environments [11413-41]

$114130 \mathrm{X} \quad$ Human-robot teaming with human intent prediction and shared control [11413-43]

NOVEL AI/ML MODELS, ALGORITHMS, AND APPLICATIONS

11413 OY Automatic construction of Markov decision process models for multi-agent reinforcement learning [1 1413-44]

$114130 Z$ Multifactorial evolutionary optimization for maximizing data aggregation tree lifetime in wireless sensor networks [1 1413-45]

$1141310 \quad$ Bayesian classifier performance for realistically randomized signals [11413-46]

1141311 Performance assessment of a machine-learning-derived digital RF communication classifier [1 1413-47]

$1141312 \quad$ Al and ML in the multi-domain operations era: vision and pitfalls (Invited Paper) [11413-48]

1141313 Augmenting wave-kinematics algorithms with machine learning to enable rapid littoral mapping and surf-zone state characterization from imagery [11413-49]

1141314 Artificial intelligence for emergency management [11413-50]

\section{AUTONOMOUS MANEUVER IN COMPLEX ENVIRONMENTS}

1141315 Aerial-ground vehicle path coordination algorithms for monitoring applications [11413-51]

1141316 Toward fieldable human-scale mobile manipulation using RoMan [11413-52]

1141317 Towards cognitive vehicles: location cognizance [11413-53]

1141318 An integrated perception pipeline for robot mission execution in unstructured environments [1 1413-54]

1141319 Routing of an unmanned vehicle for classification [11413-55] 


\section{EXPLAINABLE AND AI-ENABLED ANALYTICS}

11413 1B Explanation systems for supporting loBT-based C5ISR applications [1 1413-57]

$114131 \mathrm{~A} \quad$ A framework for explainable deep neural models using external knowledge graphs [11413-73]

JOINT SESSION WITH CONFERENCES 11413 AND 11425: AI/ML AND UNMANNED SYSTEMS

$114131 \mathrm{H} \quad$ Obstacle avoidance and navigation utilizing reinforcement learning with reward shaping [11413-12]

JOINT SESSION WITH CONFERENCES 11413 AND 11426: AI/ML AND XR

$1141311 \quad$ Cluster analysis of deep embeddings in real-time strategy games [11413-16]

\section{POSTER SESSION}

$114131 \mathrm{~J} \quad$ Object detection on aerial imagery to improve situational awareness for ground vehicles [11413-62]

$114131 \mathrm{~K} \quad$ Maneuverability hazard detection and localization in low-altitude UAS imagery [11413-64]

$114131 \mathrm{~L} \quad$ Evaluating deep road segmentation techniques for low-altitude UAS imagery [11413-65]

$114131 \mathrm{M} \quad$ Lateral control of a convoy of vehicles with a limited preview information [1 1413-66]

$114131 \mathrm{~N} \quad$ Multi-agent collaboration with ergodic spatial distributions [1 1413-67]

1141310 Modeling the sequential behaviors of online users in recommender systems [11413-68]

$114131 \mathrm{~A} \quad$ Application of the TensorFlow object detection API to high speed videos of pyrotechnics for velocity calculations [11413-70]

11413 1R Multicore processors and GPUs: the power of parallel computing in the Cloud [11413-71]

11413 is Negative ties network-based modeling of terrorist incidents [11413-72] 
$114131 \mathrm{~T} \quad$ A comparison of language representation models on small text corpora of scientific and technical documents [11413-74]

$114131 \mathrm{U} \quad$ Moving target defense for in-vehicle software-defined networking: IP shuffling in network slicing with multiagent deep reinforcement learning [1 $1413-76]$

$114131 \mathrm{~V} \quad$ Modeling a multi-segment war game leveraging machine intelligence with EVE structures [11413-78]

$114131 \mathrm{~W} \quad$ Self-updating models with error remediation [11413-79]

$114131 Y \quad$ An FPGA implementation of a self-adaptive genetic algorithm [11413-81]

1141320 Securing autonomous system in multi-domain tactical environment [1 1413-83]

$1141321 \quad$ Comparison of skeleton models and classification accuracy for posture-based threat assessment using deep-learning [1 1413-84]

1141322 Machine learning based automatic threat level assessment in fiber-optic Distributed Acoustic Sensing (DAS) intrusion detection system [1 1413-87] 
Proc. of SPIE Vol. 11413 1141301-8

\section{Downloaded From: https://www.spiedigitallibrary.org/conference-proceedings-of-spie on 25 Apr 2023
Terms of Use: https://www.spiedigitallibrary.org/terms-of-use}

